\title{
CMEARTICLE
}

\section{Clinics in diagnostic imaging (164)}

Sook Chuei Wendy Cheong $^{1}$, MBBS, Bak Siew Steven Wong ${ }^{1}$, MBChB, MMed

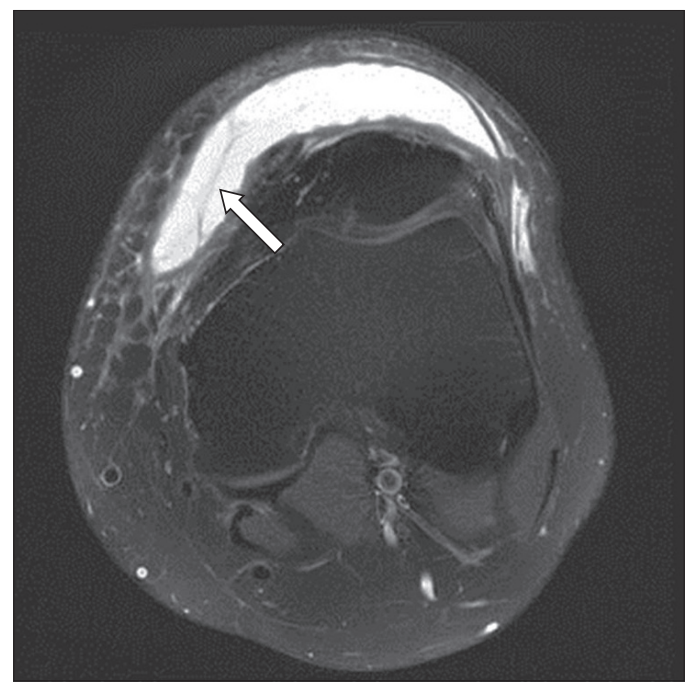

Fig. 1 Axial T2-W turbo spin-echo fat-saturated MR image of the left knee joint.
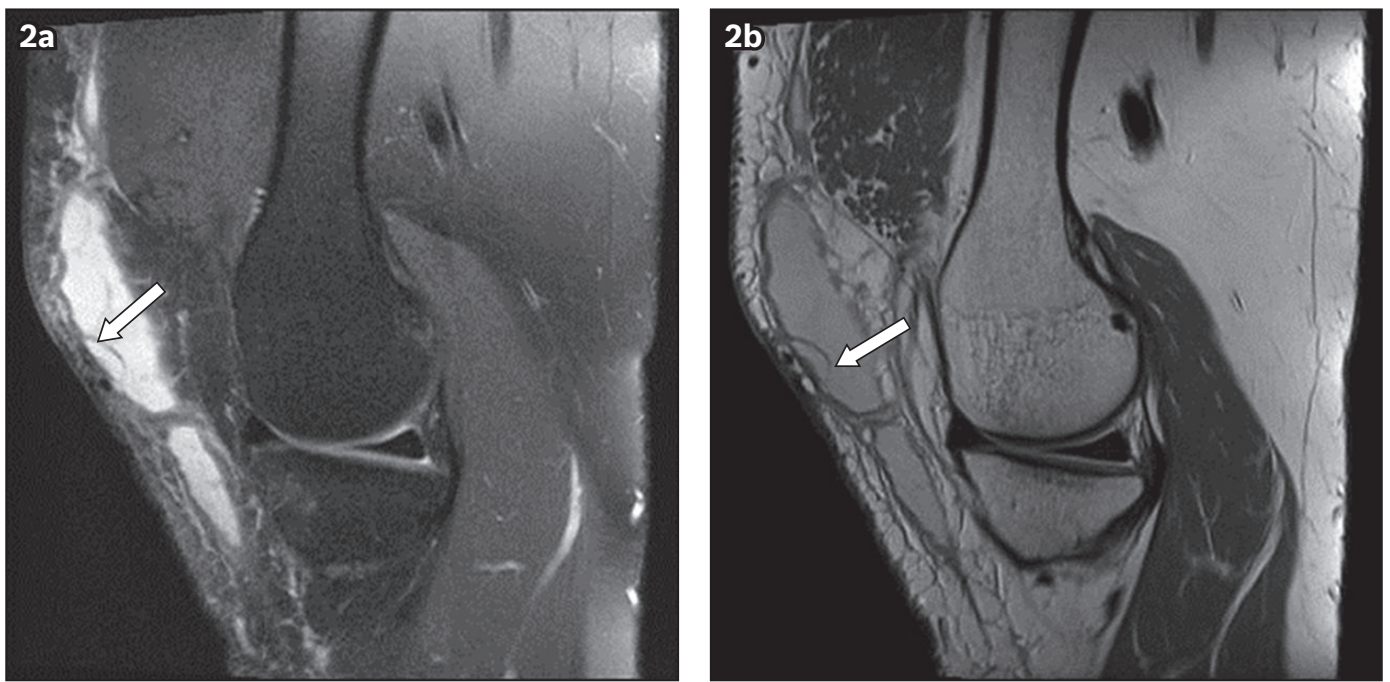

Fig. 2 (a) Sagittal PD turbo spin-echo fat-saturated and (b) $1.7 \mathrm{~mm}$ PD turbo spin-echo MR images of the left knee joint.

\section{CASE PRESENTATION}

A 31-year-old male motorcyclist presented to the emergency department after hitting the side of a car. He had been travelling at approximately $50 \mathrm{~km} / \mathrm{h}$. The patient sustained blunt trauma to the left knee and bilateral upper limb abrasions. He was alert and conscious on his arrival at the emergency department.

Physical examination of the left knee revealed superficial abrasions and swelling over the patella. Anterior and posterior drawer tests and stress testing of the left knee joint were negative. Plain radiography of the left knee joint demonstrated prepatellar soft tissue swelling, but no fracture was evident. The prepatellar swelling was persistent at follow-up. Magnetic resonance (MR) imaging of the left knee was performed.

What do the MR images show? What is the diagnosis? 


\section{IMAGE INTERPRETATION}

The MR images show a well-defined T2-weighted hyperintense fluid collection, sited in a prefascial location within the deep subcutaneous layers immediately overlying the left patella and patellar tendon (arrows in Figs. 1 \& 2). A thin T2-weighted hypointense wall and several internal septations are present. The overlying dermal layers show mild thickening. The left patella is intact. No patellar tendon or ligamentous injury can be detected in the rest of the MR image of the left knee joint. There is no effusion within the left knee joint.

\section{DIAGNOSIS}

Morel-Lavallée lesion.

\section{CLINICAL COURSE}

The patient was managed conservatively. The Morel-Lavallée lesion subsequently resolved with compression and physiotherapy.

\section{DISCUSSION}

A Morel-Lavallée lesion is a post-traumatic, closed, internal degloving injury that was first described by French surgeon Victor Auguste Francois Morel-Lavallée in the 19th century. ${ }^{(1)}$ It results from direct or tangential shearing forces across the surface of the skin, causing the subcutaneous tissue to be detached from the underlying fascia and creating a potential space between the hypodermis and the superficial fascia. ${ }^{(2-4)}$ These shearing forces disrupt the perforating vessels and lymphatic channels, filling the potential space with blood, lymph, debris or fat. ${ }^{(2-4)}$ In some cases, a local inflammatory reaction and granulation tissue may eventually organise to form a capsule, which can prevent resorption of the contents and lead to a persistent fluid collection. ${ }^{(5)}$ In severe cases, a large area of necrosis may also occur, with the risk of superimposed infection. ${ }^{(3,4)}$ The subcutaneous fluid collection can vary in internal composition depending on the severity of the injury, therefore resulting in different imaging appearances. Fluid accumulation due to arterial bleeding may develop rapidly, while fluid accumulation from lymphatic disruption develops much more slowly. ${ }^{(4,6)}$ Due to early presentation, Morel-Lavallée lesions with arterial bleeding can be diagnosed early, while other lesions often present late, from months to years after the initial trauma. Morel-Lavallée lesions may resolve spontaneously or persist if a capsule is present. (7) They are usually found adjacent to osseous protuberances. Commonly reported locations are along the greater trochanter, lumbar spine and periscapular region. Other locations include the flank, buttock (Fig. 3) and knee. ${ }^{(1,4,7)}$ Even though these lesions can be found in isolation, they are frequently associated with underlying fractures. Bilateral lesions have also been reported. ${ }^{(4)}$

Patients with Morel-Lavallée lesions usually present with pain, swelling and stiffness. On physical examination, a soft, fluctuant area showing contour deformity, skin discolouration, skin hypermotility and change in sensation or skin necrosis may be found. ${ }^{(8)}$ Initial investigation using plain radiography may detect a soft tissue mass and any associated fractures (Fig. 4). The
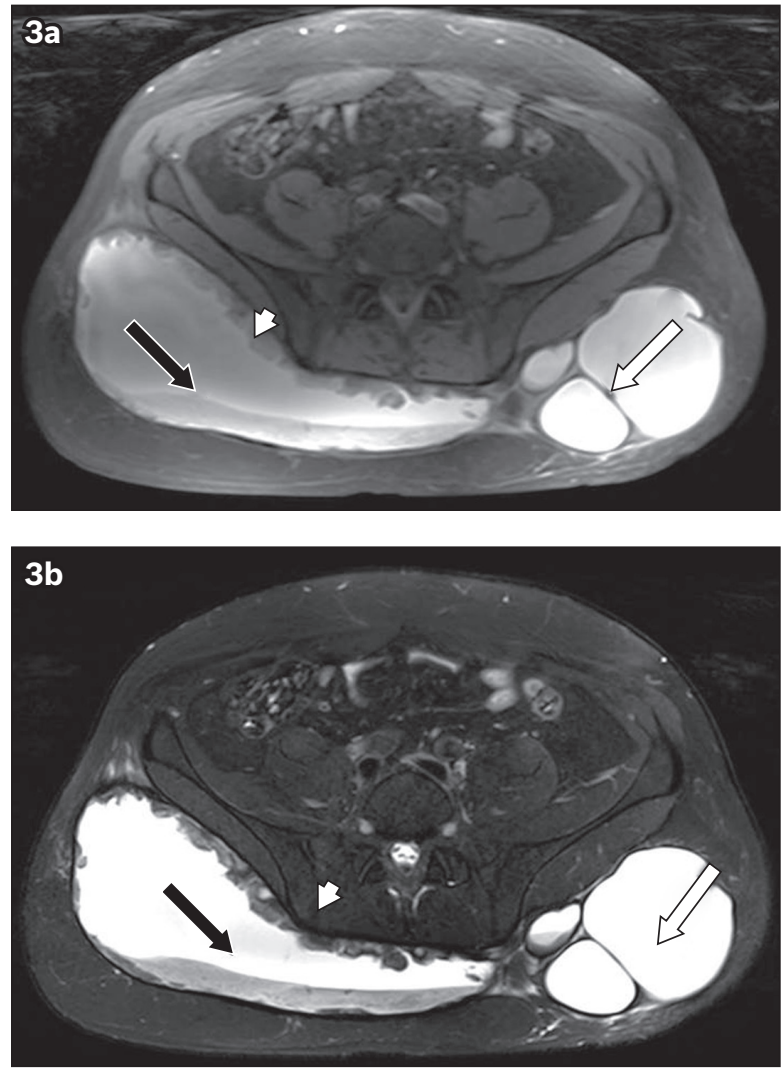

Fig. 3 (a) Axial T1-W fat-saturated and (b) T2-W fat-saturated MR images of the pelvis in a 41-year-old man who presented with a six-month history of bilateral buttock swelling. The patient had a previous history of trauma (i.e. he slipped and fell on his back). The MR images show several T1-W and T2-W hyperintense, large, well-defined, lobulated cystic lesions in the deep subcutaneous layer of both gluteal regions. Fluid-fluid levels (black arrows), internal septations (white arrows) and frond-like projections (arrowheads) in the walls of the lesion may represent remnants of fat lobules. Percutaneous drainage was performed with good response.
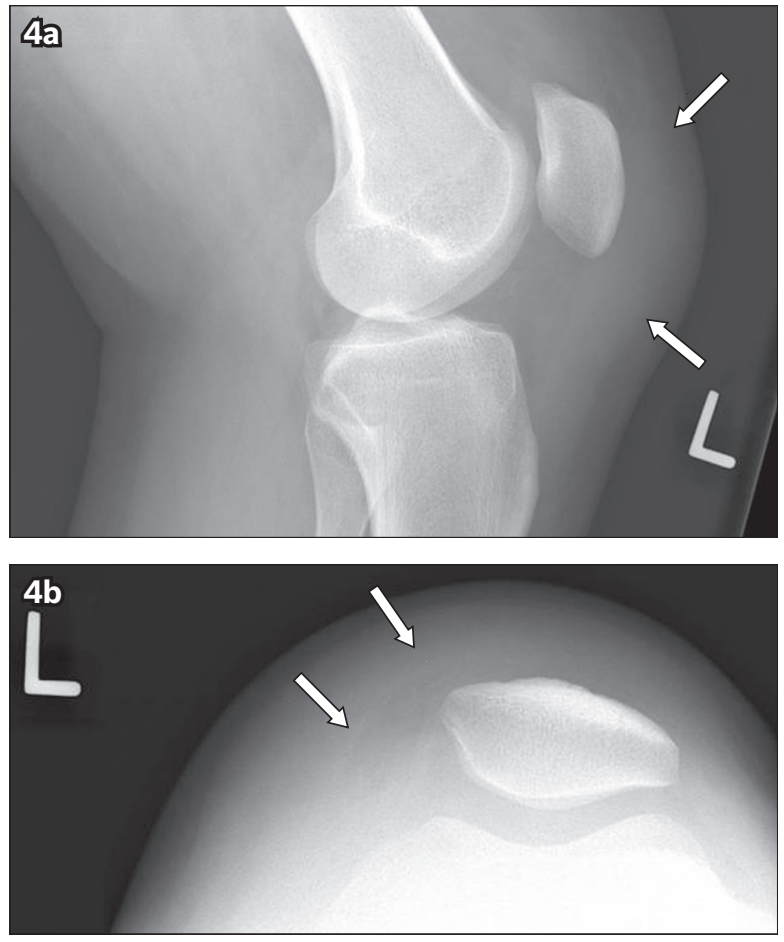

Fig. 4 Left knee plain radiographs of the patient in Fig. 1 in (a) lateral and (b) skyline projections show marked soft tissue swelling in the prepatellar region (arrows). Note the difference in thickness of the soft tissue compared to the unaffected right knee joint. 
soft tissue mass may displace the fat but does not infiltrate the layers of fat. ${ }^{(7)}$ Plain radiography may not be able to accurately ascertain the size of the soft tissue mass. It can appear as an area of radiolucency or faint radio-opacity, depending on the density of the lesion relative to the surrounding structures. Further evaluation with ultrasonography, computed tomography (CT) or MR imaging is indicated to differentiate it from a solid mass. Ultrasonography findings are variable and nonspecific, as these lesions change with time and composition. ${ }^{(2,9)}$ Morel-Lavallée lesions are located between the echogenic fascia and the hypodermis. ${ }^{(2)}$ The overlying hypodermis appears as a hypoechoic layer with thin linear echoes, within which the muscle appears as hypoechoic structures with hyperechoic lines in a pennate arrangement. ${ }^{(7)}$ The fluid collections are usually lobulated or irregularly marginated in outline and initially have a heterogeneous appearance. As the fluid collections age, they appear flatter or fusiform, becoming sonographically more homogeneous. Over time, the margins become more regular and a capsule can often be identified (Fig. 5). ${ }^{(9)}$

These lesions may appear anechoic, hypoechoic or hyperechoic depending on the composition of the collections, with blood and fat appearing more echogenic. There is no significant correlation between echogenicity and the age of a lesion. ${ }^{(9)}$ A high index of suspicion and awareness of the condition are required to differentiate Morel-Lavallée lesions from another differential diagnosis that may mimic it on ultrasonography, including acute post-traumatic haematoma, abscess, fat necrosis, neoplasm and postoperative seroma. ${ }^{(9)}$ The characteristic prefascial location of Morel-Lavallée lesions and a preceding history of trauma are important clues to reaching the correct diagnosis.

On CT, the position of the Morel-Lavallée lesions between the hypodermis and underlying fascia is clearly shown. ${ }^{(9)}$ The density of the collection is dependent on the composition, with blood being +30 to +45 Hounsfield units and fat being -50 to -100 Hounsfield units. Fluid-fluid levels have been reported, which may be due to sedimentation of cellular components in blood and/or liquefied fat. ${ }^{(5,10)}$ A hypodense pseudocapsule may develop following a local inflammatory response and can be readily seen on $\mathrm{CT}$; it may show enhancement on intravenous contrast medium (Fig. 6). The finding of a pseudocapsule is important in determining the treatment of these lesions, as encapsulated MorelLavallée lesions may not respond to conservative treatment and require surgical drainage. ${ }^{(7)}$ Three-dimensional CT reconstruction images are useful to screen for Morel-Lavallée lesions in patients with pelvic and acetabular fractures.

MR imaging is the imaging modality of choice for the evaluation and diagnosis of Morel-Lavallée lesions.(2) On MR imaging, they are well-defined and discrete, and may be oval, fusiform or crescentic in shape. ${ }^{(8)}$ The margins can sometimes taper and fuse with adjacent fascial planes. The signal intensity of the lesion is dependent on the concentration of the haemolymphatic fluid. ${ }^{(2,5)}$ Capsules, when present, may be complete or incomplete and are hypointense on all pulse sequences. ${ }^{(11)}$ Some MorelLavallée lesions may show variable enhancement on postcontrastenhanced MR imaging.

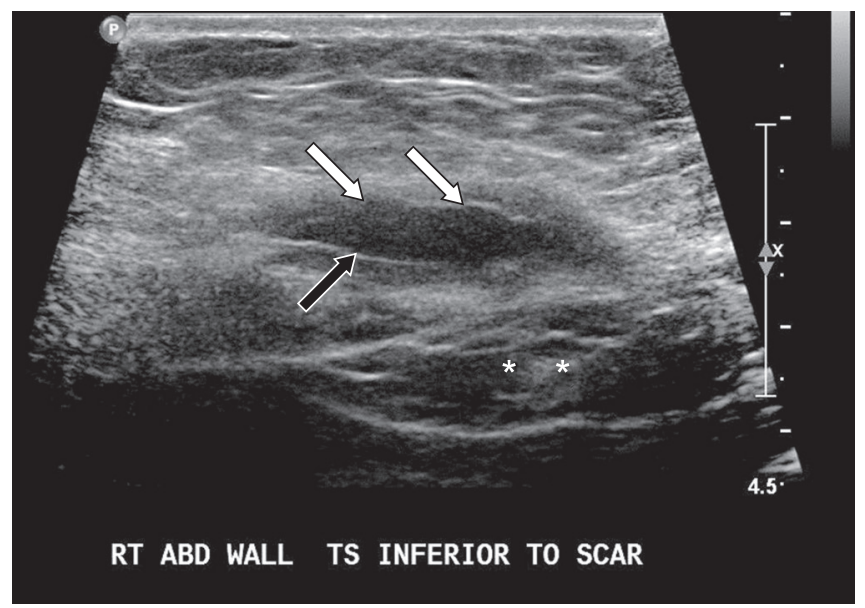

Fig. 5 A 27-year-old man presented following a road traffic accident in which he sustained a handlebar injury. Abdominal US image in transverse plane shows an encapsulated fluid collection (white arrows) within the deeper aspect of the right epigastric fat, located in the prefascial plane immediately superficial to the upper right rectus abdominis muscle $\left({ }^{*}\right)$. Note the relatively echogenic appearance of the pseudocapsule (black arrow). No internal septation, debris or vascularity is demonstrated.

An MR imaging classification system for Morel-Lavallée lesions was proposed by Mellado and Bencardino. ${ }^{(2)}$ There are six types of lesions and they are classified based on the shape of the lesion, the presence of a capsule, signal and enhancement characteristics (Table I). ${ }^{(2)}$

Morel-Lavallée lesions should be differentiated from fluid collections that appear similar, such as bursae, abscesses or intramuscular haematomas. Bursae are fluid collections occurring in known anatomical locations and are closely related to articulating joints, whereas Morel-Lavallée lesions are usually distant from joints. Unlike these lesions, bursae tend to have some synovial lining. Morel-Lavallée lesions may also be painful to the patient, but are usually not inflamed or tender to palpation in the absence of infection; patients are, in general, not significantly unwell. Their prefascial location and well-defined outlines differentiate Morel-Lavallée lesions from intramuscular haematomas.

Treatment of Morel-Lavallée lesions is dependent on the extent and severity of the underlying injury. Conservative management with compression, motion exercises and cryotherapy can be used for small acute lesions with no capsule. ${ }^{(12,13)}$ In a retrospective study of 27 Morel-Lavallée lesions of the knee by Tejwani et al, the mean time taken for such fluid collections to resolve following conservative treatment was reported to be $10.6 \pm 9.2$ days. ${ }^{(13)}$ Percutaneous drainage and sclerodesis with doxycycline and talc were found to have good outcomes in the treatment of encapsulated lesions. ${ }^{(13)}$ Aspiration of Morel-Lavallée lesions can help to relieve pain from pressure, although reaccumulation of fluid can occur post-aspiration or after an initial apparent resolution, necessitating surgery. Tejwani et al reported that Morel-Lavallée lesions requiring aspirations took $23.7 \pm 28.5$ days to resolve. ${ }^{(13)}$ Surgical management techniques, such as open debridement, can be considered for encapsulated lesions when conservative management and percutaneous treatment have failed. ${ }^{(14)}$ Antibiotic therapy is indicated for superimposed infection. 

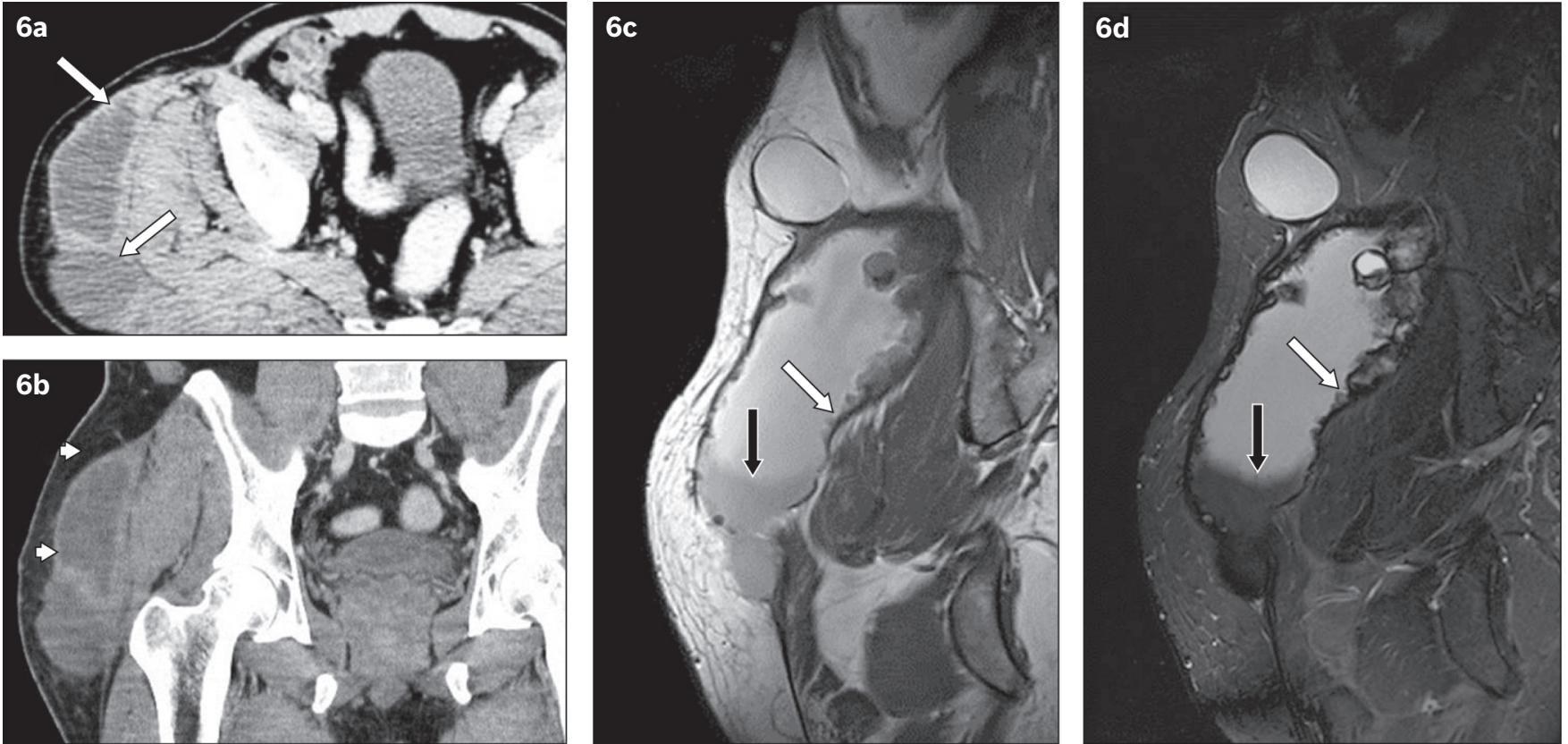

Fig. 6 A Morel-Lavallée lesion superior and lateral to the right hip joint in a 54-year-old man with a right gluteal soft tissue mass that gradually enlarged over the past four years. He sustained a contusion on the right hip in a road traffic accident nine years ago. (a \& b) Axial and coronal CT images show two large subcutaneous cystic lesions on the lateral aspect of the right greater trochanter/hip and gluteal region. The anterosuperior lesion shows a thickened capsule (white arrows), while the more inferoposterior lesion is multiloculated (arrowheads). No internal septation or fluid-fluid level is seen (c \& d) Coronal T1-W and T2-W fat-suppressed images of the right hip show several T1-W and T2-W hyperintense, large, well-defined, lobulated cystic lesions in the deep subcutaneous layer. Note the fluid-fluid levels (black arrows) and frond-like projections (white arrows).

Table I. Classification system for Morel-Lavallée lesions by Mellado and Bencardino. ${ }^{(2)}$

\begin{tabular}{|c|c|}
\hline Type & Imaging features \\
\hline 1 & $\begin{array}{l}\text { - Laminar-shaped } \\
\text { - Seroma-like lesion with no intravenous contrast } \\
\text { enhancement } \\
\text { - Low T1-weighted (T1-W) and high T2-weighted } \\
\text { (T2-W) signal intensity } \\
\text { - Capsule may be present }\end{array}$ \\
\hline 2 & $\begin{array}{l}\text { - Oval-shaped } \\
\text { - Resembles subacute haematoma with variable } \\
\text { contrast enhancement } \\
\text { - High signal intensity on both T1-W and T2-W images } \\
\text { - Thick capsule may be present }\end{array}$ \\
\hline 3 & $\begin{array}{l}\text { - Oval-shaped } \\
\text { - Resembles chronic organising haematoma with } \\
\text { internal and peripheral enhancement } \\
\text { - Intermediate intensity T1-W signal and } \\
\text { heterogeneous T2-W signal } \\
\text { - Thick capsule }\end{array}$ \\
\hline 4 & $\begin{array}{l}\text { - Linear-shaped } \\
\text { - Resembles closed laceration with variable } \\
\text { intravenous contrast enhancement } \\
\text { - Low T1-W and high T2-W signal intensity } \\
\text { - No capsule is present }\end{array}$ \\
\hline 5 & $\begin{array}{l}\text { - Round } \\
\text { - Resembles a nodule with internal and peripheral } \\
\text { enhancement } \\
\text { - Variable T1-W and T2-W signal intensity } \\
\text { - Capsule thickness varies }\end{array}$ \\
\hline 6 & $\begin{array}{l}\text { - Considered infected due to variable internal and } \\
\text { peripheral enhancement, variable T1-W and T2-W } \\
\text { signal intensity } \\
\text { - Thick capsule } \\
\text { - Sinus tract formation may occur }\end{array}$ \\
\hline
\end{tabular}

\section{CONCLUSION}

Morel-Lavallée lesions are closed, internal degloving injuries after a traumatic injury that result in detachment of subcutaneous tissues from the underlying fascia, creating a potential space that is filled with haemolymphatic fluid of any combination. Given the complex and variable appearance of Morel-Lavallée lesions, MR imaging is the diagnostic imaging modality of choice. The presence of a capsule is an important radiologic finding as lesions with capsules are unlikely to respond to conservative management.

ABSTRACT A 31-year-old male motorcyclist presented with prepatellar swelling of the left knee after a collision with a car. Magnetic resonance imaging of the knee showed no bony or ligamentous injury to the knee. Instead, a well-defined, thin-walled, T2-weighted hyperintense fluid collection with internal septations was identified in a prefascial location overlying the left patella and patellar tendon. The findings were in keeping with those of a Morel-Lavallée lesion, a closed internal degloving injury. Morel-Lavallée lesions are occasionally encountered after a blunt soft-tissue trauma. The presentation and imaging features are discussed.

Keywords: internal degloving injury, Morel-Lavallée lesion, prefascial fluid accumulation

\section{REFERENCES}

1 Morel-Lavallée. [Décollements traumatiques de la peau et des couches sous jacentes]. Arch Gen Med 1863; 1:20-38, 172-200, 300-32. French.

2. Mellado JM, Bencardino JT. Morel-Lavallée lesion: review with emphasis on MR imaging. Magn Reson Imaging Clin N Am 2005; 13:775-82. 
3. Hudson DA, Knottenbelt JD, Krige JE. Closed degloving injuries: results following conservative surgery. Plast Reconstr Surg 1992; 89:853-5.

4. Hak DJ, Olson SA, Matta JM. Diagnosis and management of closed internal degloving injuries associated with pelvic and acetabular fractures: the Morel-Lavallée lesion. J Trauma 1997; 42:1046-51.

5. Borrero CG, Maxwell N, Kavanagh E. MRI findings of prepatellar MorelLavallée effusions. Skeletal Radiol 2008; 37:451-5.

6. Kottmeier SA, Wilson SC, Born CT, et al. Surgical management of soft tissue lesions associated with pelvic ring injury. Clin Orthop Relat Res 1996; (329):46-53.

7. Parra JA, Fernandez MA, Encinas B, Rico M. Morel-Lavallée effusions in the thigh. Skeletal Radiol 1997; 26:239-41.

8. Carroll JF. Morel-Lavallée Lesions. In: MRI Web Clinic - June 2010 [online]. Available at: http://radsource.us/morel-lavallee-lesions/. Accessed September 2, 2014
9. Neal C, Jacobson JA, Brandon C, et al. Sonography of Morel-Lavallee lesions. J Ultrasound Med 2008; 27:1077-81.

10. Gilbert BC, Bui-Mansfield LT, Dejong S. MRI of a Morel-Lavellée lesion. AJR Am J Roentgenol 2004; 182:1347-8.

11. Mellado JM, Pérez del Palomar L, Díaz L, Ramos A, Saurí A. Long-standing Morel-Lavallée lesions of the trochanteric region and proximal thigh: MRI features in five patients. AJR Am J Roentgenol 2004; 182:1289-94.

12. Harma A, Inan M, Ertem K. [The Morel Lavallée lesion: a conservative approach to closed degloving injuries]. Acta Orthop Traumatol Turc 2004; 38:270-73. Turkish

13. Tejwani SG, Cohen SB, Bradley JP. Management of Morel-Lavallee lesion of the knee: twenty-seven cases in the national football league. Am J Sports Med 2007; 35:1162-7.

14. Tseng S, Tornetta P 3rd. Percutaneous management of Morel-Lavallee lesions. J Bone Joint Surg Am 2006; 88:92-6. 


\section{SINGAPORE MEDICAL COUNCIL CATEGORY 3B CME PROGRAMME} (Code SMJ 201601B)

Question 1. Regarding the Morel-Lavallée lesion:

(a) It is a closed, internal degloving injury resulting in separation of the fascia and muscle.

(b) It contains blood or blood products, lymph, debris or fat globules.

(c) It can always be identified within the first 24 hours after trauma.

(d) Common locations include the flank, buttock and knee regions.

Question 2. Regarding the Morel-Lavallée lesion:

(a) It is always associated with underlying fractures.

(b) It is located in the prefascial plane.

(c) A well-defined hypoechoic lesion in the prefascial plane on ultrasonography is a diagnostic feature.

(d) It does not show enhancement on $\mathrm{CT}$.

Question 3. A differential diagnosis of Morel-Lavallée lesions includes:
(a) Acute post-traumatic haematoma.
(b) Intramuscular haematoma.
(c) Periarticular bursa.
(d) Postoperative seroma.

Question 4. On magnetic resonance imaging:

(a) Morel-Lavallée lesions always show a high T2-weighted signal.

(b) Fluid-fluid level, septations and capsular wall may be demonstrated.

(c) The capsular wall is hypointense.

(d) Morel-Lavallée lesions always show contrast enhancement.

Question 5. Regarding treatment of Morel-Lavallée lesions:

(a) Physiotherapy and lesion compression are effective for all lesions.

(b) All patients should be given prophylactic antibiotics.

(c) Percutaneous drainage is sufficient for Morel-Lavallée lesions with no capsule present.

(d) Surgical debridement is an option when conservative management or percutaneous treatment has failed.

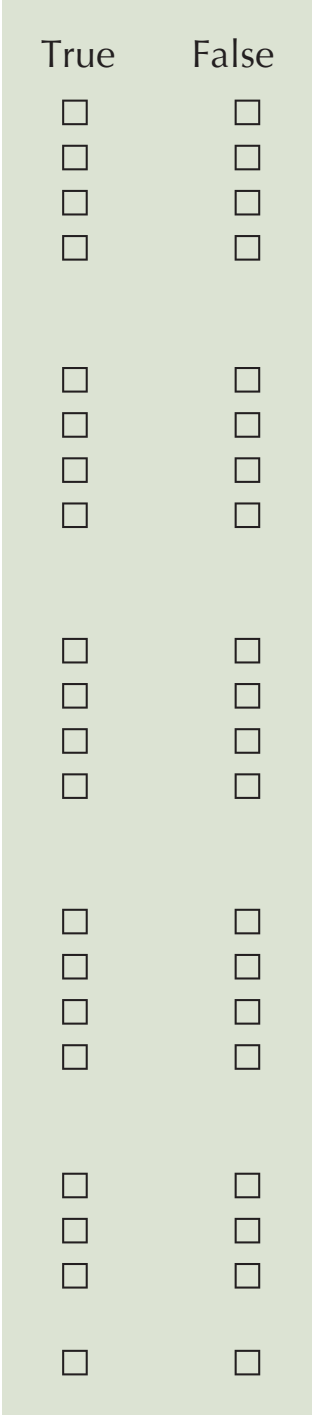

\footnotetext{
Doctor's particulars:

Name in full

MCR number

Specialty:

Email address

\section{SUBMISSION INSTRUCTIONS:}

(1) Log on at the SMJ website: http://www.sma.org.sg/publications/smjcurrentissue.aspx and select the appropriate set of questions. (2) Provide your name, email address and MCR number. (3) Select your answers and click "Submit".

RESULTS:

(1) Answers will be published in the SMJ March 2016 issue. (2) The MCR numbers of successful candidates will be posted online at the SMJ website by 4 March 2016. (3) Passing mark is $60 \%$. No mark will be deducted for incorrect answers. (4) The SMJ editorial office will submit the list of successful candidates to the Singapore Medical Council. (5) One CME point is awarded for successful candidates.

Deadline for submission: (January 2016 SMJ 3B CME programme): 12 noon, 26 February 2016.
} 